Andrews University

Digital Commons @ Andrews University

Honors Theses

Undergraduate Research

$12-5-2018$

\title{
A Survey on the Effectiveness of the Flipped Classroom in the Communication Sciences
}

Amanda Bange

Andrews University

Follow this and additional works at: https://digitalcommons.andrews.edu/honors

Part of the Educational Methods Commons

\section{Recommended Citation}

Bange, Amanda, "A Survey on the Effectiveness of the Flipped Classroom in the Communication Sciences" (2018). Honors Theses. 197.

https://dx.doi.org/10.32597/honors/197

https://digitalcommons.andrews.edu/honors/197

This Honors Thesis is brought to you for free and open access by the Undergraduate Research at Digital Commons @ Andrews University. It has been accepted for inclusion in Honors Theses by an authorized administrator of Digital Commons @ Andrews University. For more information, please contact repository@andrews.edu. 


\title{
J. N. Andrews Honors Program Andrews University
}

\section{HONS 497}

Honors 'Thesis

A Survey on the Effectiveness of the Flipped Classroom in the Communication Sciences

\author{
Amanda Bange
}

December 5, 2018

\author{
Dr. Darah Regal \\ Dr. Karl Bailey
}

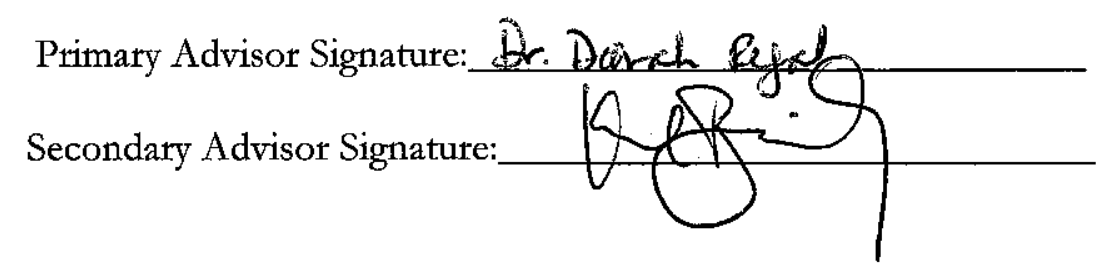




\begin{abstract}
This study examines how the flipped classroom model impacts student performance in the communication sciences. The flipped classroom is defined as an educational technique that utilizes technology to provide lecture materials outside of class time, while students complete projects and engage in discussion in class with the professor. Twenty-six participants responded to a survey regarding their flipped classroom experiences in four spring semester speechlanguage pathology and audiology classes. Responses were mixed, indicating a dislike of the formatting of the style while appreciating the extra practice, question-and-answer time, and thorough engagement with the topic that the flipped classroom model provided.
\end{abstract}

Introduction

The use of technology in education has been a topic of much interest and debate in recent years, with countless studies dedicated to proving its efficacy, or lack thereof, in the students' educational experience (Tamim et. al., 2011). At the same time, differentiating instruction to assist in the academic achievement of underperforming students who do not connect with traditional lecture styles has also been a topic of attention as of late (Anderson \& Algozzine, 2007; Pashler et. al., 2008). As a way to combine these two things, technology and diverse learning styles, educators have turned to "flipping the classroom," a strategy first introduced in 1998 by Barbara Walvoord and Virginia Johnson Anderson in the book Effective Grading. Not long after, Maureen Lage, Glenn Platt, and Michael Treglia added technology to this model, exposing students to lecture videos and PowerPoints before class time (2000). The terminology for this technique has several iterations, but for the sake of simplicity it will be henceforth referred to as the flipped classroom, and will be defined as "an educational technique that 
consists of two parts: interactive group learning activities inside the classroom, and direct computer-based individual instruction outside the classroom" (Bishop \& Verleger, 2013).

The flipped classroom has shown its effectiveness in many different branches of learning. McLaughlin et al. found that it enhanced learning in a basic pharmaceuticals course (2014). Bishop and Verleger found that in engineering courses, using a flipped classroom increased performance on exams (2013), as did Tune, Sturek, and Basile in a graduate level cardiovascular, respiratory, and renal physiology course (2013). It has been suggested that this increase in performance is due to the model's encouraging students to learn actively (Jenson, Kummer, Godoy, 2015). While this can be seen in the aforementioned disciplines, the research into flipped classroom in communication sciences is limited. A study done in a business course may demonstrate that flipping the classroom may not be as effective in some disciplines as others (Findlay-Thompson \& Mombourquette, 2014). Hence, further research into what works for communication sciences is merited. A 2015 study done on an Introduction to Audiology class reveals that flipped exam scores increased significantly at the end of the semester compared to a nonflipped cohort. However, the same instructor taught both courses simultaneously, and so instructor bias cannot be ignored (Berg et al., 2015). A study done in an Anatomy and Physiology for Speech and Swallowing course found that active learning in both flipped and nonflipped classes resulted in similar final grades regardless of format (Lemoncello, 2015). This seems to imply that students must be actively participating in content to score higher in their classes, and can do well in either format if thusly engaged. What students prefer in terms of pedagogical style may then have an impact on how well they learn the material.

I hypothesized that, regardless of intrinsic motivation to actively learn or attitudes concerning the style of the class, the flipped classroom in communication sciences forces 
students to actively participate in content, which is exhibited in their final grades. To test this hypothesis, I have created a survey that compares student attitudes and feelings about the flipped style to their final grades in the class.

\section{Methodology}

Subjects were students enrolled in four Spring 2018 semester classes in the department of Speech Language Pathology and Audiology that used a traditional class format supplemented by varying degrees of the flipped classroom technique. Components of this included podcasts, video lectures, online quizzes, or other learning materials to be completed before class, with interactive learning activities in class. Students in these classes were given a consent form at the beginning of the survey, as well as asked to input their Student ID number as a personal identifier. These personal identifiers were translated into code on the webpage prior to being stored on the server.

Students consenting to the survey filled it out electronically. The participants were asked questions regarding their perceptions of the flipped classroom and its effectiveness with respect to the traditional format. The survey took no more than fifteen minutes. The professors of the class were asked to input Student ID numbers with the corresponding final grade in the class, which was translated into code prior to being stored on the server.

Survey questions were taken from previous studies conducted by Birdville Schools and the Library Orientation Exchange. Said organizations used these questions to draw valid conclusions based on the data collected from them, which will also be accomplished by this study.

The researchers examined correlations between the grades as reported by professors and items on the first section of the survey. The final section of open-ended questions was analyzed by looking for themes across participants. 


\section{Results}

Results were analyzed using the SPSS statistics program, and each question analyzed from the survey was correlated using a Pearson correlation coefficient and analyzed for significance with a two-tailed p-value. Two of the three professors submitted their grades for this analysis, and only students from these classes who responded to all of the following questions were included. Interestingly, results were significant at $\mathrm{p} \leq 0.01$ level for only one question of the survey. No other result was significant, not even at a comparatively reduced standard of $\mathrm{p} \leq 0.05$. As demonstrated later, this is the question that received the greatest variation of responses, with students claiming divisively that the course was or was not helpful to them.

The questions analyzed for correlations are as follows:

1. The flipped class style makes it easier to understand the course content.

2. The flipped approach has helped me learn more than I would have if we had used in class lecture and discussion methods only.

3. The course modules (videos and readings) are beneficial in preparing for class.

4. The in-class work has helped me to learn class content.

5. It is helpful to do exercises in class when other students and the professor are available to answer my questions, as opposed to doing them by myself.

6. I feel that I have been provided with enough resources to study for quizzes and exams.

7. I have learned class content thoroughly enough to explain to a peer.

8. How often do you watch the videos on time?

The first seven questions required students to respond with one of five choices that were assigned a numeric value- Strongly Disagree (1), Disagree (2), Unsure (3), Agree (4), Strongly 
Agree (5). The last question had response options in the same manner. Students could select Never (1), Rarely (2), Sometimes (3), Often (4), and Always (5). The final grades in the class were then assigned value on a similar scale, with each letter grade represented by a number, such as a 4 for an A, 3 for a B, and so forth for correlation in SPSS. Figure 1 shows the results of analyzing these questions.

Figure 1.

\begin{tabular}{|l|l|l|l|l|l|l|l|l|}
\hline $\begin{array}{l}\text { Question } \\
\text { Number }\end{array}$ & $\mathbf{1}$ & 2 & 3 & 4 & 5 & 6 & 7 & $\mathbf{8}$ \\
\hline Pearson & $\mathbf{. 6 3 6}$ & .418 & .197 & .033 & .021 & .137 & .329 & .168 \\
\hline Significance & $\mathbf{. 0 0 6}$ & .095 & .448 & .900 & .938 & .599 & .197 & .519 \\
\hline
\end{tabular}

It is clear that the first question, bolded for convenience, both correlates most strongly and is the most, nay only, significant result. This demonstrates that the students who did well in the class also responded more positively to the class style when it comes to comprehending course content. The second question, that flipped class helped students learn more, was the next strongest correlation and closest to significance, but is still relatively weak and not significant at a $p \leq 0.05$ level. The other questions which address specifics of the style, are only very weakly correlated, including the question about watching videos in time for class, which sought to measure class engagement. The absence of significance and very weak correlation on this question indicating that active participation in the style had little to no effect on the final grade of the student.

The individual results of this survey, measured by percentages of responses were mixed, demonstrating a dislike for lectures outside of class but an appreciation for extra assistance and 
hands-on activities in the classroom. Some examples of how the students responded as a class can be found in Figures 2-4 below.

Figure 2

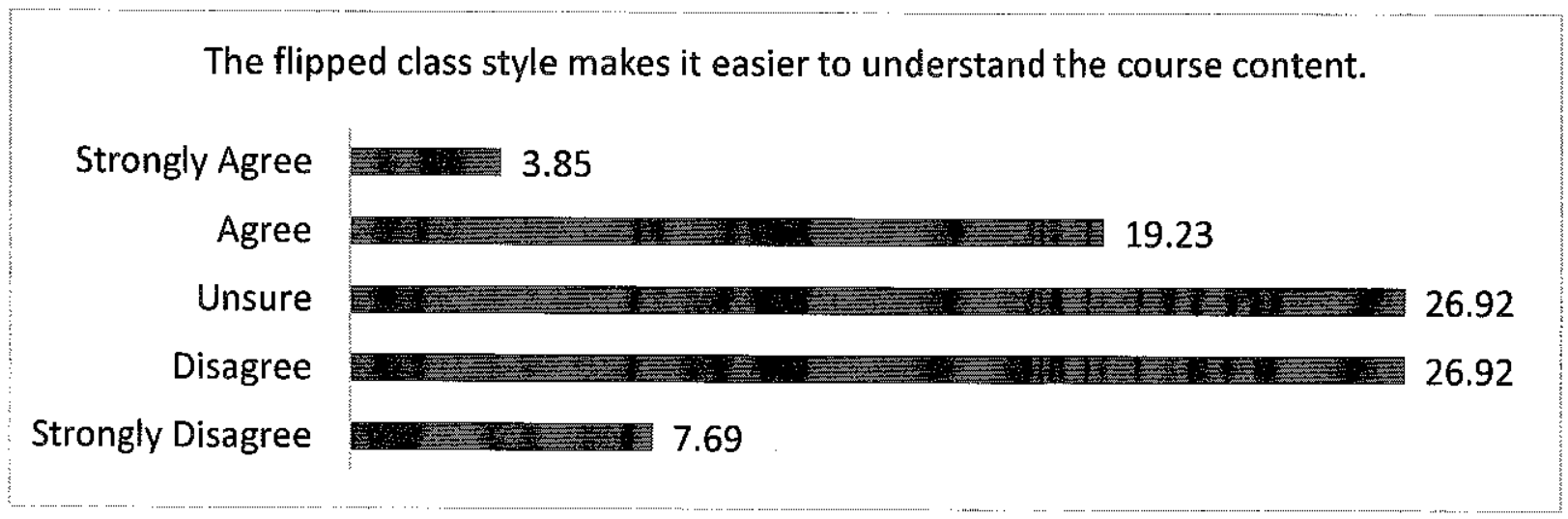

Figure 3

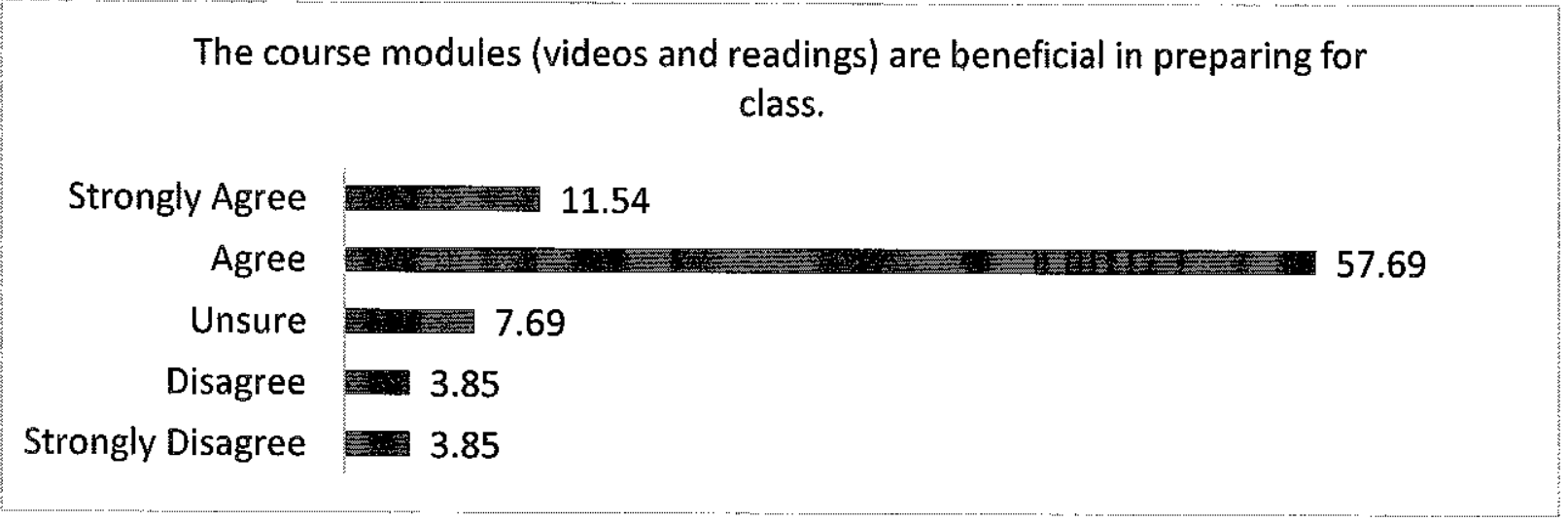

Figure 4

How often do you watch the videos on time?

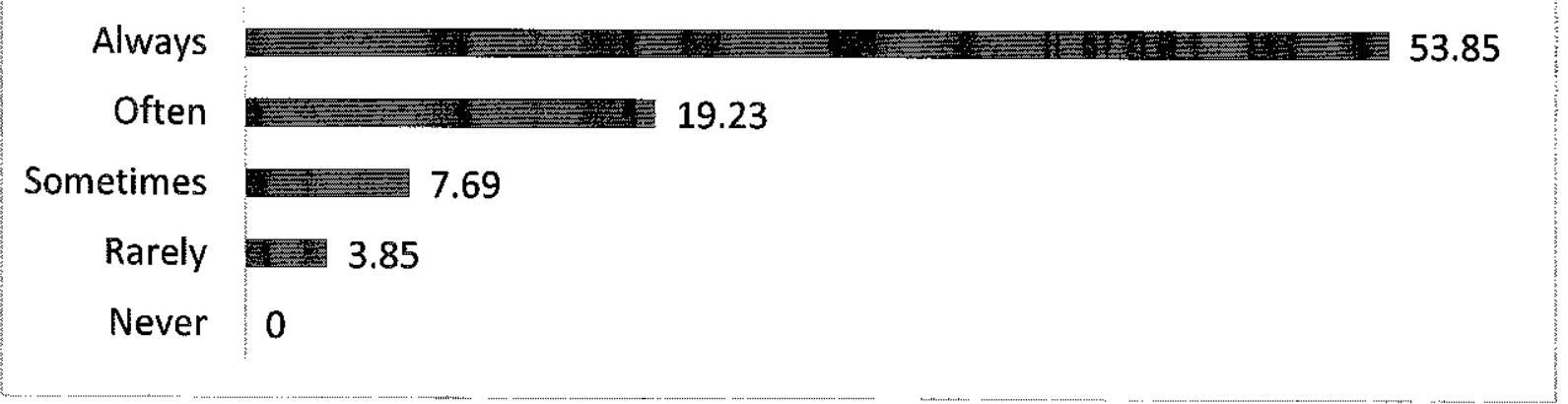


These next two examples had very interesting responses that contain valuable information on their own but also speak to the validity of the survey. See Figure 5.

Figure 5

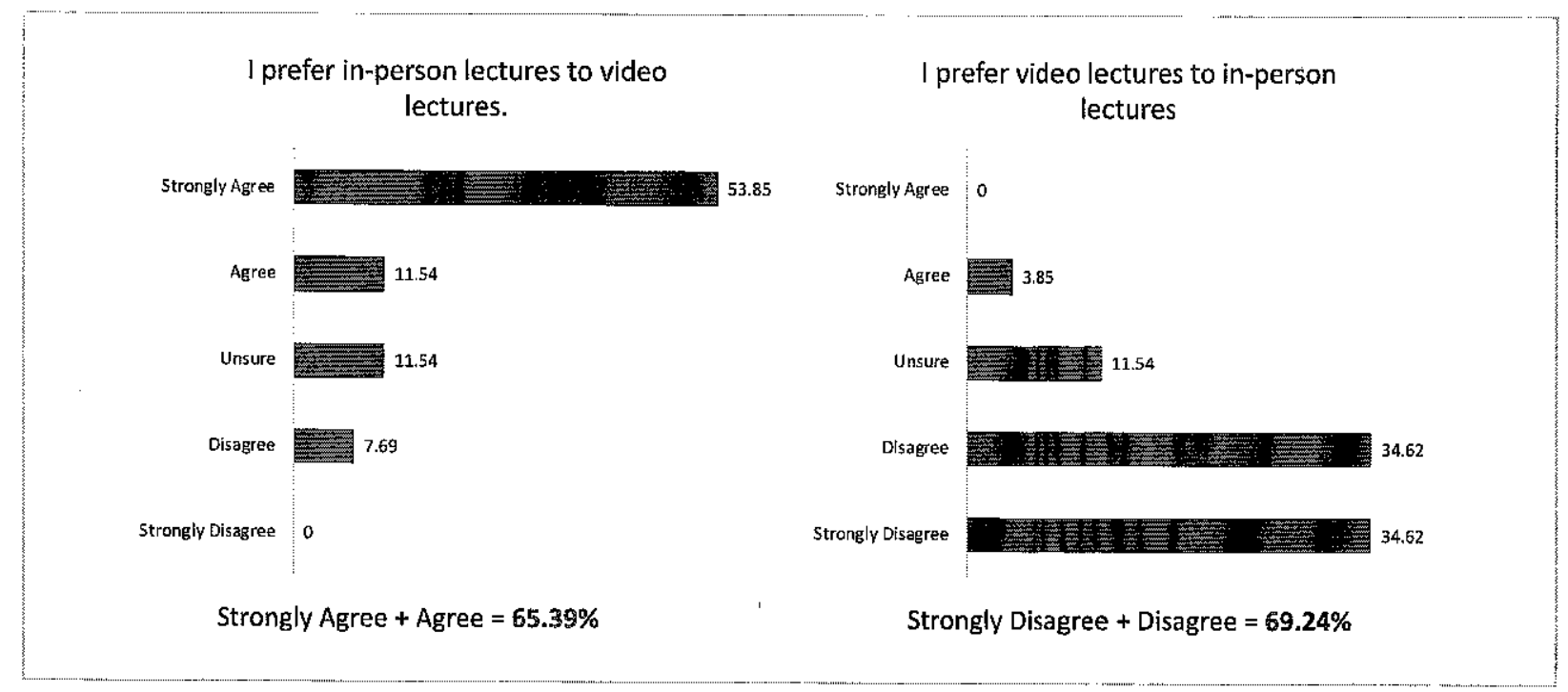

These two statements are exact opposites of one another- "I prefer in-person lectures to video lectures," and "I prefer video lectures to in-person lectures." Responses to these two were consistent as a whole. One can see that when students are asked if they prefer in person lectures, they overwhelmingly agree, with $53.85 \%$ selecting strongly agree and $11.54 \%$ selecting agree. These two measures are within one degree of separation, and if combined, come out to $65.39 \%$. Some were unsure but very few said that they would disagree. For the opposite, with "I prefer video lectures" first, responses have similar percentages overall. Strongly disagree and disagree, also within one degree of separation, total $69.24 \%$. These similar totals demonstrate that the students who responded to the survey actually read the questions asked before responding, rather than the alternative of selecting random responses.

For the second set of questions, students were asked to move a slider bar to give a percentage of their engagement. See Figure 6 for a summary of their average responses and standard deviations. 
Figure 6

\begin{tabular}{|c|c|c|}
\hline Question & Average & Standard Deviation \\
\hline $\begin{array}{c}\text { How confident did you feel } \\
\text { about the material after } \\
\text { watching the videos but } \\
\text { BEFORE coming to class? }\end{array}$ & 57 & 25 \\
\hline $\begin{array}{c}\text { How confident did you feel } \\
\text { about the material after } \\
\text { watching the videos but } \\
\text { AFTER coming to class? }\end{array}$ & 78 & 20 \\
\hline $\begin{array}{c}\text { How much effort have you } \\
\text { been putting in during your } \\
\text { time outside of class? }\end{array}$ & 70 & 23 \\
\hline $\begin{array}{c}\text { How much effort have you } \\
\text { been putting in during your } \\
\text { time in class? }\end{array}$ & 79 & 18 \\
\hline
\end{tabular}

As shown here, students have self-reported that they had in increase in understanding after coming to class, which is consistent with the idea implied by the other questions that they did not feel comfortable with the video lectures. After class they were much more confident that they learned the material. One can also see that the standard deviation has decreased from before class to after in the first two questions, showing that the responses were closer together in confidence after class overall. It is important to note that these are self-reported measures by the students. This is how much they themselves feel that they are participating in the class material.

For the final section of the survey, open ended responses have been evaluated for common themes. Here are some of the most common ideas found in their responses. Students indicated that:

Discussion time was especially helpful to understanding.

Being able to re-watch the videos increased comprehension. 
Not being able to ask questions mid-lecture was frustrating.

Increased collaboration and practical application was appreciated.

For the flipped classroom, in-class activities were the best use of class time.

Flipped classroom incorporated different types of learning- visual, auditory, and handson- which cemented academic concepts.

These responses confirm what is demonstrated in the rated questions, that students felt the flipped classroom was beneficial in the extra resources and hands-on learning it affords, but still have trouble appreciated the online lectures before class.

\section{Conclusions}

The results of the Pearson correlation seem to suggest, to a small extent, that student attitudes about the flipped classroom did relate to their final grades in the class. However, because of the lack of correlation and significance in the majority of questions, this theory will need deeper and repeated study. One important limitation to this part of the study was the small class size and even lesser student response to the survey. For more accurate results, a larger group of participants would be ideal in future studies. Another limitation to the study is that students who responded to the survey had relatively high grades in the B to A range. Students who did not do well in the class completed the survey in lesser numbers. This discrepancy would have an impact on the correlations as reported in this study. An observation to note is that for these students who did not do well, the flipped classroom may not be effective and thus they were not inclined to take the survey.

The individual responses to the survey also indicate that the flipped classroom is an effective teaching style for the communication sciences for these students. Responses to rated 
questions showed that while students preferred a traditional lecture style, the online portions were useful in preparing for class and exams. Open-ended responses confirm this, with answers tending toward appreciation for resource material but a dislike of lectures outside the classroom. These results combined suggest that students perceive the flipped classroom model to be helpful to their overall learning experience, despite misgivings about the formatting. A limitation to note for this section of results is the inexperience of the professors teaching the flipped style and the minimal exposure of the students participating. The flipped classroom was a new experience for both professor and student. Future study should evaluate a more settled pedagogical interpretation of the flipped classroom. However, despite these limitations, this survey and its responses do provide valuable information to any professor or department seeking to pursue this style of education in the future, particularly within the communication sciences but also in the broader academic community. 


\section{Bibliography}

Anderson, K. \& Algozzine, B. (2007). Tips for teaching: Differentiating instruction to include all students. Preventing School Failure, 51 (3), 49-54.

Berg, A. L., Ibrahim, H., Magaster, S., \& Salbod, S. (2015). Flipping over the flipped classroom. Contemporary Issues in Communication Science and Disorders, 42, 16-25. NSSLHA.

Birdville Schools. (2018). Retrieved from https://www.birdvilleschools.net/cms/lib2/TX01000797/Centricity/Domain/842/Flipped \%20Classroom $\% 20$ Student $\% 20$ Survey $\% 20$ pie\%20charts.pdf

Bishop, J. \& Verleger, M. (2013). The flipped classroom: A survey of the research. American Society for Engineering Education. 1-18.

Findlay-Thompson, S. \& Mombourquette, P., (2014). Evaluation of a flipped classroom in an undergraduate business course. Business Education \& Accreditation, 6 (1), 63-71.

Jensen, J., Kummer, T., \& Godoy, P. (2015). Improvements from a flipped classroom may simply be the fruits of active learning. CBE-Life Sciences Education, 14, 1-12.

Lage, M.J., Platt, G.J., \& Treglia, M. (2000). Inverting the classroom: A gateway to creating an inclusive learning environment. The Journal of Economic Education 31. 30-43.

Lemoncello, R. (2015). Blended, active learning for anatomy \& physiology: Development \& program evaluation. SIG 10 Perspectives on Issues in Higher Education, 18, 62-75. doi:10.1044/ihe18.2.62

Library Orientation Exchange. (2018). Retrieved from http://www.loex.org/quarterly_extras/393_WoottonColborn_Survey.pdf

McLaughlin, J., Roth, M., Glatt, D., Gharkholonarehe, N., Davidson, C., Griffin, L., ... Mumper, R. (2014). The flipped classroom: A course redesign to foster learning and 
engagement in a health professions school. Academic Medicine, 89 (2), 236-243. doi: 10.1097/ACM.0000000000000086

Pashler, H., McDaniel, M., Rohrer, D., \& Bjork, R. (2008). Learning styles: Concepts and evidence. Psychological Science in the Public Interest, 9, 103-119.

Tamim, R., Bernard, R., Borokhovski, E., Abrami, P., \& Schmid, R. (2011). What forty years of research says about the impact of technology on learning: A second-order meta-analysis and validation study. Review of Educational Research, 81 (1). 4-28, https://doi.org/10.3102/0034654310393361

Tune, J., Sturek, M., \& Basile, D., (2013). Flipped classroom model improves graduate student performance in cardiovascular, respiratory, and renal physiology. American Physiological Society. https://oi.org/10.1152/advan.00091.2013

Walvoord, B.E., and Anderson, V.J. (1998). Effective grading: A tool for learning and assessment. San Francisco: Jossey-Bass. 